\title{
Analysis on the Reasons of Social Responsibility Management Deficiency of Multinational Corporations' Supply Chain Based on PDCA Model
}

- a Case Study of Apple Company

Jin Chen ${ }^{1, a}$ and Haiqing Bai $^{2, b^{*}}$

${ }^{1}$ Department of Commerce in Xiamen City University, Xiamen, 361008, China

${ }^{2}$ School of Journalism and Communication, Xiamen University, Xiamen, 361005, China.

a181357314@qq.com, bHaiqing.bai@xmu.edu.cn

*The corresponding author

Keywords: Multinational enterprise; Supply chain; Social responsibility

\begin{abstract}
Under the environment of global economic integration, many large multinational corporations outsource production to suppliers in developing countries, however, some moral problems often occur during the production process of these suppliers. In view of this, multinational corporations will enhance supply chain management, but the reality is still not satisfactory. Based on PDCA model, taking Apple Company as the example, this article analyzes the causes of social responsibility management deficiency of multinational corporations'supply chain. According to the analysis, the causes of social responsibility management deficiency of Apple's supply chain are as follows: social responsibility requirement formulation based on deficiency of procedural justice and result justice, relying on strict supervision rather than relationship management to supervise suppliers to fulfill their social responsibilities, primarily relying on internal inspection instead of external inspection, unresponsive to external exposure incidents. This analysis has a certain degree of inspiration to other multinational companies on social responsibility management of supply chain.
\end{abstract}

\section{Introduction}

As economic globalization sweeps on, in order to minimize cost and improve competitive edge of products, multinational companies tend to allocate resources worldwide, do global purchase and global distribution. Efficient supply chain management of transnational corporations is one of the important sources of its core competencies. However, in recent years, social responsibility misadministration of supply chain corporations occurs frequently in the management process of transnational companies, which has huge negative effect on the reputation of transnational corporations and brings great impact for transnational corporations' management. Because of transnational corporation's leading position in the global industrial chain and excellent business reputation, public expect multinational companies take more social responsibility in supply chain management. As the most innovative company in the world, Apple enjoys good global reputation for its excellent product performance, but there are many omissions in its social responsibility of supply chain. Based on PDCA (Plan, Do, Check and Act, a continual improving management model), this article analyzes these oversights thoroughly, and provides a useful reference for multinational companies to discharge supply chain social responsibility, obtain trust and support from supply chain stakeholders, promote product and responsibility value.

\section{Literature Review}

In recent years, the study of supply chain social responsibility has gradually emerged. Early scholars introduce the concept of social responsibility into supply chain management, they consider the core enterprises in upstream and downstream of supply chain should take social responsibility. Poist (1989), the scholar who first puts forward supply chain social responsibility thinks that 
responsibility issues have to be considered in supply chain as a whole [1] Some scholars analyze the different stages of the supply chain development, and point out that at any stage of supply chain development, the lack of corporate social responsibility will seriously damage company's reputation (Fabian, 2000) [2]. Some scholars believe that corporate performing supply chain social responsibility can not only promote healthy competition in supply chain, but also effectively reduce waste, promote technical innovation, improve cost performance and improve social recognition, thus promotes the healthy development of enterprises (Simpson and Power, 2005) [3]. Some scholars believe that the evaluation of supply chain's sustainability can avoid risk, increase efficiency of supply chain, increase stakeholders' understanding of corporate accountability and build corporate reputation (Gualandris et al, 2015) [4].

Scholars also make some research on the strategy of how to implement social responsibility in supply chain relationships. Boiral (2003) finds that companies let enterprises in the supply chain perform social responsibility through three main tools: social label, socially responsible investing and the code of conduct. Social label informs public that this company implements some social responsibility standards, such as Starbucks Standards, it buys coffee from coffee farmers directly; socially responsible investing means companies investing the supply chain enterprises who focus on social responsibility; the code of conduct is enterprises develop a set of behavior standards to select and restraint suppliers. If core enterprise supervises its suppliers does not comply with the code of conduct, it will cancel cooperation relationship [5]. D. Eric Boyd (2007) thinks that for buyers, instead of strictly supervising discharge of social responsibility of upstream enterprises, it is better to carry on transaction according to fair procedure, and that makes it easier to let the supply chain enterprises obey rules and fulfill their social responsibilities [6]. Bowon (2008) believes that the ideal responsibility supply chain should be based on the governance structure of matched responsibility and benefit, and enterprises in supply chain should establish more positive, active supply chain coordination and linkage mechanism [7]. Jiang's (2009) research indicates relational governance of core enterprise to supply chain enterprises can perfectly adjust the relationship among price pressure, product complexity, contract period and suppliers' commitment to perform social responsibility [8]. Parmigiani, Klassen \& Russo (2011) think that enterprises in supply chain need to well undertake environmental and social responsibility, and the interference (control and accountability) of stakeholders plays a very important role in it [9].

With the prevalence of globalized production, enterprises in upstream and downstream of supply chain form close network in production process. Because of multinational companies' leading and core position in network, they can extend social responsibility to entire network through supply chain management. Promoting corporate social responsibility in global supply chain is not only an extension of core corporates' social responsibility management, but also important content of upstream and downstream enterprises integrating enterprise relationship (Christian, 2008[10]; Esben, 2006[11]). Although most scholars affirm positive results of multinational corporations implementing social responsibility management in global supply chain, many studies suggest that because of extreme power asymmetry in governance structure of global supply chain, supply chain social responsibility management does not produce the anticipated results. Because it is essentially a negative unilateral arrangement, and its core purpose is to transfer risks of buyers' labour rights protection and social responsibility to downstream suppliers (Liang Xiaohui, 2009).

According to the above literature, currently educational field has reached a consensus on positive effect of supply chain social responsibility, but the study of how multinational corporations in core position of supply chain better carrying out its supply chain social responsibility is relatively deficient. Based on the analysis of failed causes in fulfilling social responsibilities for transnational corporations, this article provides appropriate countermeasures and suggestions for it.

\section{Analysis on the Reasons of Social Responsibility Management Deficiency of Multinational Corporations' Supply Chain Based on PDCA Model}

PDCA model introduction. PDCA model is called quality cycle, first put forward by Shewhart in 1930. In 1950, U.S. quality management expert Dr. Deming excavated PDCA model again, and 
widely disseminated and used it in the process of continuous improvement of product quality. PDCA consists of the first letters of these English words: Plan, Do, Check and Action, and PDCA cycle is a scientific procedure conducting quality management in accordance with this order circularly. More specifically, PDCA model consists of four steps: (1) P (plan) includes policies and objectives determination, and formulation of activity plan. (2) D (Do), based on known information, design specific method, plan and layout; Then according to design and layout, carry on concrete operation to realize target content. (3) C (check), summarize the results of implementation plan, distinguish right from wrong, clear effects and find out problem. (4) A (action), process the summarized inspection results and affirm experience of success and standardize them; Also sum up failures to bring them to the attention. For unresolved issues, they should be submitted to the next PDCA cycle to resolve. These four processes do not run over once, but again and again, after one cycle, some problems solved, and unresolved problems enter the next cycle and step up.

PDCA model figure is as follows:

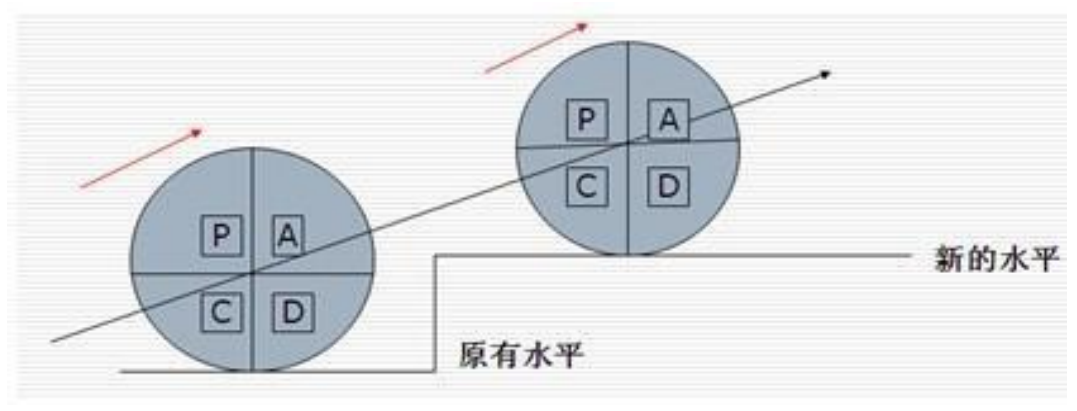

Figure 1. PDCA model

Based on PDCA model, we can analyze that the causes of social responsibility management deficiency of Apple's supply chain are:

Plan Stage: Social Responsibility Requirements Formulation on the Basis of Result Justice and Procedure Justice Deficiency. In Apple's case, from the first part of PDCA model--plan stage, in developing social responsibility requirements for suppliers, Apple does not comply with the principles of result justice and the principle of procedure justice.

From the perspective of result justice, the requirement of result justice is coordinated principle of responsibility and benefit. But when Apple develops social responsibility rules for suppliers, because of Apple's pursuit of excellence, it sets extremely high demands for suppliers' social responsibility, but it does not take additional costs into account when suppliers perform social responsibility, and only gives suppliers very narrow profit margin. In the case of many suppliers competing for Apple's orders, some suppliers are willing to take the risk through illegal technical process or operation with production costs as low as possible, and this leaves behind hidden danger for social responsibility management deficiency of Apple's supply chain in the future. For example, Apple has high standards for product quality, if the product has slight scratch, it can pass in other electronics companies, but it would be returned under Apple's strict testing standards. If suppliers want to improve production efficiency and yield, additional cost is required. On the other hand, suppliers need to spend a lot of money to improve the situation of supply chain responsibility and pay the high cost of factory audit, which in turn increases their cost. But at the time of Apple's profit distribution, the profit level of suppliers is very low. Take iPhone as an example, Apple company occupies $58.5 \%$ profits, while labour cost in China accounts for only $1.8 \%$ in each iPhone. In this pattern, suppliers are likely to violate Apple's supplier code in order to reduce costs.

From the aspect of procedure justice, the requirement of procedure justice is stakeholders can express their demands in decision making process, and carry on the full consultation and communication. However, in the rule-making process of Apple's supply chain guidelines, rewards and punishments, with the enormous advantages of capital, research and development, brand and consumer loyalty, Apple enjoys the highest power in supply chain; On the contrary, due to its large 
number and the competition for orders, suppliers are in a relatively weak position in supply chain and they do not have enough discourse power. Therefore, in the situation of lacking appropriate checks and balances, Apple is more likely to lean interest allocation of whole supply chain to itself, and this creates imbalance in profits distribution of supply chain.

Because of result justice and procedure justice deficiency, the formulation of Apple's social responsibility standards has the tendency of unfairness.

Do Stage: It Is Hard to Obtain Commitments by Supervision. In the process of supply chain management, Apple's main management concept is by supervision rather than relational interaction to supervise suppliers to perform social responsibility code. According to scholar's related research, rigid supervision cannot guarantee suppliers' commitment to social responsibility. Only when suppliers and core enterprise establish common goals and shared values, and regard themselves and core enterprise as a community of interests, it is easier for suppliers to fulfill their commitment to social responsibility. Apple has a huge network of suppliers, but it does not carry on effective relational management to suppliers, so it is hard to obtain loyalty of suppliers only by supervision.

From "Supplier Responsibility Report" issued by Apple, we can see that Apple has a strict check system of supply chain social responsibility, each audit is led by Apple auditor, with the help of professional trained third party auditor. During the process, Apple randomly selects factories, carrying out audit without advance notice, and it attaches great importance to major irregularities, then reports directly to Apple executive team of suppliers to deal with it immediately. During the audit process, Apple conducts in-the-spot investigation and view documents, and it carries on interviews with workers in their mother tongue in the case of avoiding managers. After that, workers will get a phone number in order to give them the opportunity to safely provide more feedback about factory to Apple team in private, including anything they consider immoral behavior. Apple encourages workers to report any retaliation behavior, it will follow up with the supplier to ensure that each issue is properly addressed. In addition, in order to strict audit process, the number of times for auditing continues to increase, in 2014, Apple conducted 633 audits in 19 countries or regions, which has been the highest number since 2006.

Even Apple's review process is so rigorous, a lot of problems still came out in supply chain. For example, Guangdong Pingzhou Electronics Factory, a supplier of Apple circuit board components, uses of child labor on assembly line. These children are all arranged by Shenzhen's largest labor organization, Shenzhen Quanshun human resource company, and this company has prepared related files for these juveniles. In Apple's supplier responsibility report released in 2011, many suppliers have problems like falsified records, bribing auditors and abetting workers how to answer auditors' questions. According to the supplier social responsibility report released in 2015 , there are 73 factories having underage workers working or working overtime, 105 factories not pay enough overtime payment to workers as required in law, and 94 factories not provide workers with full insurance. In terms of 633 times of audit, these data also belong to relatively high proportion.

Thus it can be seen, Apple's supply chain management concept of control and audit needs to be changed to that of relationship and audit.

Check Stage: Rejection to outside Inspection. Apple's inspection of supply chain social responsibility primarily relies on internal audit and rejects external information, which is associated with Apple's confidential culture. The book "Inside Apple" says Apple enjoys worldwide reputation and has unparalleled global influence, but at the same time, Apple's product examination, confidential work is also rare. Apple's product performance is remarkable, in order to avoid being imitated by competitors and give consumers more surprises in product release meeting, Apple has established strict confidential culture. Apple thinks confidentiality is closely related to productivity, and this creed challenges the long-standing virtue of trust and transparency in the management. Internal performance of confidentiality is monitoring staff and initial distrust, and external performance of that is high degree confidentiality of information to supply chain enterprises. Thus, during the inspection of supply chain corporates for social responsibility, Apple relatively rejects surveillance from public and third party, and greatly restricts the pressure from public scrutiny. For suppliers, pressure from customers is delivered by Apple, and the absence of supervision from other 
stakeholders (like public) reduces constraints on suppliers' social responsibility.

In August 2011, 5 Chinese non-government environmental protection agencies, including Friends of Nature, IPE, Green Beagle, Enviro-friends and Green Stone in Nanjing jointly released a research report "The Other Side of Apple: Pollution Spreads Under the Dark Veil". The report has in-the-spot investigations to "suspected" Apple suppliers in Wuhan, Nanjing, Taiyuan and other places, and it focuses on many Apple's supply chain factories, also questions that Apple's supply chain of purchasing product and components not only causes environmental pollution in surrounding areas, also makes workers cripple due to poisoning and affects the health of local residents. This pollution map of Apple supply chain in China not only exposes 27 "suspected" Apple suppliers, but also points out that Apple Company suppliers in China bring huge environmental problems. It also points out that behind Apple's fashion products, the price is "poisoning environment, damaging community, sacrificing interests of workers". The main author of "The Other Side of Apple", the Director in Beijing Institute of Public and Environment, Ma Jun indicates multi information displays Apple involves in supply chain management deep, from materials to the control of dust standard in production process. How great impact of these interventions on pollution and poisoning, Apple has the duty to disclose and explain. But either way, Apple still insists on its own opinion and refuses to publicize any problems of its supply chain.

Besides, environmental organizations have repeatedly accused Apple has violations on suppliers and its continual use of polluting enterprises as suppliers, but Apple responds these questions like "our long-term policy is not to disclose suppliers". From these cases, we can see that under the influence of confidential culture, Apple refuses to communicate with public. This makes Apple as suppliers' endorsement indirectly, which weakens public supervision power and hides unethical behavior of suppliers.

Action Stage: Passive Action to External Examination. In the aspect of supply chain social responsibility, Apple issues supply chain social responsibility report every year, and proposes corrective actions to the problems existing in social responsibility last year. Overall, Apple is a very disciplined company and attaches great attention to problems in supply chain management. It also takes measures like supporting, helping and punishing to some problematic suppliers. Moreover, since 2014 suppliers' social responsibility reports include suppliers' substantive progress in transparency of supply chain social responsibility. In addition, Apple provides skill training for workers and managers to improve their management capacity, and these are substantive progress. But even so, Apple tends to be quite passive to external checks, so this hinders improvements in Apple's supply chain social responsibility. At the beginning of 2009, as one of Apple's suppliers, Wintek produced Apple's touch-screen, after receiving large order, it used chemical solvent nhexane in place of alcohol, and let employees to wipe phone screen. Hexane is used in LCD production line, and it evaporates more easily than alcohol, which is a better cleaning agent. But at the same time it is a kind of narcotic, which attacks human's nervous system. It was reported that workers began to have headaches and dizziness, and ultimate performance was serious nerve injury, then many people ended up in hospital. Doctors diagnosed that the cause of nerve injury might lie in cleaning touch-screen with n-hexane. After 137 staff "being poisoned", many media carried on track report and triggered "Poisonous Apple" storm. Although the issue of poisoned workers and problem of Apple supplier Wintek were very clear, Apple did not respond this in a timely and clearly manner. According to SACOM survey, "Poisonous Apple" event began at 2009, but Wintek and Apple handled this event extremely slowly. In 2011, Apple mentioned this event for the first time in Apple's annual working condition of global supplier investigative report. According to the report, its supplier used toxic chemical hexane on making phone's screen, and 137 workers got hurt, so Apple had required its suppliers to stop using n-hexane and to improve factory occupational safety. Facing reporters' interview, Apple declined to comment on Wintek's case.

Unresponsive to external exposure events and hysteretic in summary are related with Apple's confidence and character, but Apple needs to establish a more friendly public image, which also contributes it to become a more socially responsible company. 


\section{Research Conclusion}

Based on PDCA model, this article analyzes the causes of social responsibility deficiency of Apple's supply chain, and the causes of management deficiency of Apple's supply chain are as follows: social responsibility requirement formulation based on deficiency of procedural justice and result justice, relying on strict supervision rather than relationship management to supervise suppliers to fulfill their social responsibilities, primarily relying on internal inspection instead of external inspection, unresponsive to external exposure incidents. As an excellent company, Apple itself has been committed to the continuous improvement of supply chain social responsibility issues, but there are still many omissions in its supply chain management, and hope the conclusions of this study can give reference to Apple's supply chain improvement and other multinational companies' supply chain management.

\section{References}

[1] Poist R F. Evolution of Conceptual Approaches the Design of Logistics Systems: A Sequel [J]. Transportation Journal, 1989, 28(3):35-39.

[2] Fabian T. Supply Chain Management in an Era of Social and Environment Accountability [J]. Sustainable Development, 2000, (12): 27-30.

[3] Simpson D F, ower D J. Use the Supply Relationship to Develop Lean and Green Suppliers [J]. Supply Chain Management, 2005, 10(1): 60-68.

[4] Gualandris J, Klassen R D, Vachon S, et al. Sustainable Evaluation and Verification in Supply Chains: Aligning and Leveraging Accountability to Stakeholders[J]. Journal of Operations Management, 2015, 38: 1-13.

[5] Boiral O. The Certification of Corporate Conduct: Issues and Prospects [J]. International Labour Review, 2003, 142(3): 317-340.

[6] Boyd D E, Spekman R E, Kamauff J W, et al. Corporate Social Responsibility in Global Supply Chains: A Procedural Justice Perspective[J]. Long Range Planning, 2007, 40(3): 341-356.

[7] Paton R A, McLaughlin S. Services Innovation: Knowledge Transfer and the Supply Chain [J]. European Management Journal, 2008, 26(2): 77-83.

[8] Jiang B. The Effects of Interorganizational Governance on Supplier's Compliance with SCC: An Empirical Examination of Compliant and Non-Compliant Suppliers [J]. Journal of Operations Management, 2009, 27(4): 267-280.

[9] Parmigiani A, Klassen R D, Russo M V. Efficiency Meets Accountability: Performance Implications of Supply Chain Configuration, Control, and Capabilities [J]. Journal of Operations Management, 2011, 29(3): 212-223.

[10] Schaefer B P. Shareholders and Social Responsibility [J]. Journal of Business Ethics, 2008, 81(2): 297-312.

[11]Pedersen E R, Andersen M. Safeguarding corporate social responsibility (CSR) in global supply chains: how codes of conduct are managed in buyer-supplier relationships [J]. Journal of Public Affairs, 2006, 6(3-4): 228-240. 